\title{
Evaluation of Radiosurgery Target Volume Determination for Meningiomas Based on Computed Tomography (CT)
}

\section{And Magnetic Resonance Imaging (MRI)}

\author{
Omer Sager $^{1}$, Ferrat Dincoglan ${ }^{1}$, Selcuk Demiral ${ }^{1}$, Murat Beyzadeoglu ${ }^{1}$ \\ ${ }^{1}$ Department of Radiation Oncology; University of Health Sciences, Gulhane Medical Faculty, Ankara, Turkey
}

Received: January 02, 2019; Accepted: January 18, 2019; Published: January 29, 2019

*Corresponding author: Omer Sager, University of Health Sciences, Gulhane Medical Faculty, Department of Radiation Oncology, Gn.Tevfik Saglam Cad. 06018, Etlik, Kecioren, Ankara, Turkey, E-mail: omersager@gmail.com

\begin{abstract}
Objective: Meningiomas arise from arachnoid cap cells and comprise the commonest benign tumor of the brain, accounting for more than one third of all intracranial neoplasms. Surgery and radiation therapy (RT) have been traditionally used in meningioma management. Radiosurgery is a sophisticated form of therapeutic irradiation with the capability of delivering high doses of radiation to well defined targets with typically steep dose gradients around the treatment volumes under robust stereotactic localization and image guidance. Target volume definition is an important part of menigioma radiosurgery. In this study, we assessed the use of multimodality imaging for target volume definition in radiosurgery of meningiomas.

Methodology: We included 27 patients receiving meningioma radiosurgery at our department. All patients were treated with high precision radiosurgery after multidisciplinary assessment of patients regarding lesion size, location, association with critical neurovascular structures, symptomatology, and previous treatments. Target volume determination was done based on using only CT images and also by incorporation of MR fusion to perform a comparative assessment.
\end{abstract}

Results: Comparative evaluation revealed improved target volume definition by incorporation of MRI into radiosurgery treatment planning for patients treated with radiosurgery for meningiomas.

Conclusion: Improved target definition is a pertinent goal of optimal radiosurgical treatment planning. Our study supports the utility of MRI in meningioma radiosurgery treatment planning. Clearly, further research is warranted to refine target definition for radiosurgical management of meningiomas.

Key words: Meningioma; Radiosurgery; Magnetic Resonance Imaging (MRI)

\section{Introduction}

Meningiomas arise from arachnoid cap cells and comprise the commonest benign tumor of the brain, accounting for more than one third of all intracranial neoplasms [1,2]. Meningiomas are typically benign tumors with an indolent disease course in the majority of patients, however, they may also cause severe symptoms depending on their location and association with nearby critical structures. Meningiomas may be located at several locations in the brain including the cavernous sinus, foramen magnum, cerebellopontine angle, olfactory groove, cerebral convexities, parasagittal/falx cerebri, intraventricular, intraorbital, sphenoid wing, petrous ridge, suprasellar region, tentorium, and posterior fossa. World Health Organization (WHO) classification is widely used for meningiomas. Benign, WHO grade I meningioma subtypes include the meningothelial, psammomatous, fibrous, transitional, secretory, microcystic, metaplastic, and lymphoplasmocyte-rich types [3]. WHO grade II and WHO grade III meningiomas have a lower incidence $[3,4]$. WHO grade II meningiomas include the chordoid, clear cell, and atypical meningiomas [3,4].WHO grade III meningiomas include the rhabdoid, papillary, and anaplastic types $[3,4]$. Due to the benign and indolent nature of the majority of menigiomas, a considerable number of patients may be observed with any intervention reserved for progression and occurrence of symptomatology. Nevertheless, meningiomas may cause a wide spectrum of symptoms depending on their location and association with critical neurovascular structures. Surgery and radiation therapy (RT) have been traditionally used in meningioma management [5]. Complete surgical removal has been standard if feasible, resulting in prompt resolution of meningioma related symptoms. RT plays a central role as a complementary or definitive treatment modality. Higher grade meningiomas have a high tendency for recurrence even after comprehensive surgical resection, which renders adjuvant RT a viable adjuvant therapeutic option for these patients [5]. A recent study has supported the use of RT for management of newly diagnosed WHO grade II meningiomas after gross total resection and for management of recurrent WHO grade I meningiomas to achieve improved local control [6]. 
Radiosurgery in the forms of Stereotactic Radiosurgery (SRS), Fractionated Stereotactic Radiotherapy (FSRT), Hypofractionated Stereotactic Radiotherapy (HFSRT), and Stereotactic Body Radiation Therapy (SBRT) has emerged as a viable radiotherapeutic modality for management several benign and malign tumors throughout the human body including meningiomas, brain metastases, arteriovenous malformations, pituitary adenomas, vestibular schwannomas, cerebral cavernous malformations, craniopharyngiomas, glomus jugulare tumors, pulmonary oligometastases, and recurrent glioblastomas [7-25].

Primary advantage of radiosurgery is the ability to deliver high dose of radiation to well defined targets with typically steep dose gradients around the treatment volume under robust stereotactic localization and image guidance. This contemporary treatment modality offers high precision management of several intracranial and extracranial tumors with a condensed treatment schedule along with a favorable toxicity profile. In the context of meningiomas, several studies have reported the safety and efficacy of radiosurgery as a complementary and definitive treatment modality for meningiomas [14,23,25-27].

Target volume definition plays a central role in radiosurgical treatments. Multimodalityimaging may be utilized for determining radiosurgery treatment volumes [28]. For radiotherapeutic management of meningiomas, Magnetic Resonance Imaging (MRI) has been utilized for several purposes including detection, localization and target definition, lesion characterization, differentiation of meningioma grades based on imaging features, prediction of clinical agressiveness, assessment of treatment response and prognosis [29-36]. In this context, we evaluated the incorporation of Magnetic Resonance Imaging (MRI) into target volume definition for radiosurgery of meningiomas in this study.

\section{Materials and Methods}

We identified 27 patients receiving meningioma radiosurgery at our department. All patients were treated with high precision radiosurgery after multidisciplinary assessment of patients regarding lesion size, location, association with critical neurovascular structures, symptomatology, and previous treatments. Computed Tomography (CT) simulation was performed at the CT simulator (GE Lightspeed RT, GE Healthcare, Chalfont St. Giles, UK) at our department under stereoactic immobilization. Slice thickness was 1.25 for acquiring the planning images at the CT simulator, while a thin slice MRI was also performed for all patients using $1 \mathrm{~mm}$ slice thickness, typically within one week before radiosurgical treatment. CT simulation images were transferred to the contouring workstation (SimMD, GE, UK) for delineation of target volume and surrounding critical organs. Target volume determination was done based on using only CT images and also by incorporation of MR fusion to perform a comparative assessment. Determination of ground truth target volume for actual treatment and comparison purposes was performed by the expert group of treating physicians after thorough evaluation, collaboration and consensus using data from both CT and MRI. While ERGO ++ (CMS, Elekta, UK) treatment planning system was used for radiosurgery planning, treatments were delivered using Synergy (Elekta, UK) Linear Accelerator (LINAC) under stereotactic localization and image guidance with kV-CBCT (kilovoltage Cone Beam CT) and XVI (X-ray Volumetric Imaging, Elekta, UK).

\section{Results}

A total of 27 patients were included in the analysis. Median target volume was $8.1 \mathrm{cc}$ (range: 2.3-31.8 cc) with CT-only imaging, $8.6 \mathrm{cc}$ (range: 2.4-32.7 cc) with CT-MR fusion based imaging, and $8.5 \mathrm{cc}$ (range: 2.4-32.5 cc) on consensus decision of all treating physicians with collaborative comprehensive assessment and colleague peer review. The ground truth target volumes decided by the expert group of treating physicians after thorough evaluation, collaboration and consensus using data from both CT and MRI were consistent with target definition based on CT-MR fusion based imaging in majority of the patients, and incorporation of MR images resulted in improved delineation of the meningioma lesions with less interobserver variability. Figure 1 illustrates planning CT and MR images of a patient with meningioma.

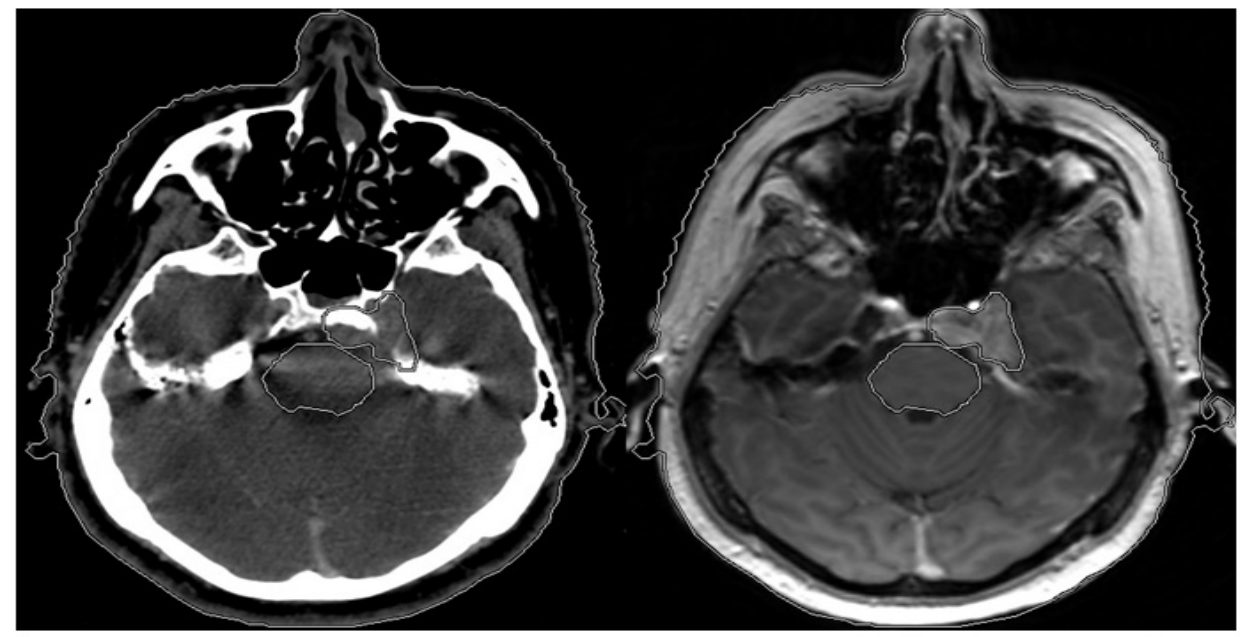

Figure 1: Planning CT and MR images of a patient with meningioma 


\section{Discussion}

Decision making for optimal treatment of meningiomas requires close collaboration among experts in neurosurgery, neuroradiology, and radiation oncology. Individual evaluation should be performed by the multidisciplinary team considering lesion size and location, association with critical neurovascular structures, patient age, availability of resources, logistical issues, patient symptomatology and preferences. If treatment with radiosurgery is decided, vigilance is required for target volume determination since radiosurgical treatments typically deliver high fractional doses for local control of the meningioma lesions. Precision in target definition is warranted to achieve an improved toxicity profile along with durable local control. In this context, multimodality imaging may facilitate accurate targeting through providing improved contrast resolution. MRI may add to the accuracy of contouring the meningioma lesions. While CT achieves improved assessment of bony anatomy, MRI remains to be a viable imaging modality for identification of the dural tail in meningiomas.

\section{Conclusion}

Improved target definition is a pertinent goal of optimal radiosurgical treatment planning. Our study supports the utility of MRI in meningioma radiosurgery treatment planning. Clearly, further research is warranted to refine target definition for radiosurgical management of meningiomas.

\section{References}

1. Ostrom QT, Gittleman H, Xu J, Kromer C, Wolinsky Y, Kruchko C, et al. CBTRUS Statistical Report: Primary Brain and Other Central Nervous System Tumors Diagnosed in the United States in 2009-2013. Neuro Oncol. 2016;18(suppl_5):v1-v75. doi: 10.1093/neuonc/now207

2. Wiemels J, Wrensch M, Claus EB. Epidemiology and etiology of meningioma. J Neurooncol. 2010;99(3):307-314. doi: 10.1007/ s11060-010-0386-3

3. Harter PN, Braun Y, Plate KH. Classification of meningiomas-advances and controversies. Chin Clin Oncol. 2017;6(Suppl 1):S2. doi: 10.21037/ cco.2017.05.02

4. Kshettry VR, Ostrom QT, Kruchko C, Al-Mefty O, Barnett GH, BarnholtzSloan JS.Descriptive epidemiology of World Health Organization grades II and III intracranial meningiomas in the United States. Neuro Oncol. 2015;17(8):1166-1173. doi: 10.1093/neuonc/nov069

5. Rogers L, Barani I, Chamberlain M, Kaley TJ, McDermott M, Raizer J, et al. Meningiomas: knowledge base, treatment outcomes, and uncertainties. A RANO review. J Neurosurg. 2015;122(1):4-23. doi: 10.3171/2014.7.JNS131644

6. Rogers L, Zhang P, Vogelbaum MA, Perry A, Ashby LS, Modi JM, et al. Intermediate-risk meningioma: initial outcomes from NRG Oncology RTOG 0539. J Neurosurg. 2018;129(1):35-47. doi: 10.3171/2016.11. JNS161170

7. Sirin S, Oysul K, Surenkok S, Sager O, Dincoglan F, Dirican B, et al. Linear accelerator-based stereotactic radiosurgery in recurrent glioblastoma: A single center experience. Vojnosanit Pregl. 2011;68(11):961-966.
8. Dincoglan F, Beyzadeoglu M, Sager O, Oysul K, Sirin S, Surenkok S, et al. Image-guided positioning in intracranial non-invasive stereotactic radiosurgery for the treatment of brain metastasis. Tumori. 2012;98(5):630-635. doi: 10.1700/1190.13205

9. Dincoglan F, Sager O, Gamsiz H, Demiral S, Uysal B. Management of arteriovenous malformations by stereotactic radiosurgery: A single center experience. UHOD-Uluslararasi Hematoloji-Onkoloji Dergisi. 2012;22(2): 107-112.

10. Surenkok S, Sager O, Dincoglan F, Gamsiz H, Demiral S, Uysal B, et al. Stereotactic radiosurgery in pituitary adenomas: A single center experience. UHOD-Uluslararasi Hematoloji-Onkoloji Dergisi. 2012;22(4): 255-260.

11. Dincoglan F, Sager O, Gamsiz H, Uysal B, Demiral S, et al. Stereotactic radiosurgery for intracranial tumors: A single center experience. Gulhane Med J. 2012;54(3):190-198.

12. Sager O, Beyzadeoglu M, Dincoglan F, Demiral S, Uysal B, Gamsiz H, et al. Management of vestibular schwannomas with linear acceleratorbased stereotactic radiosurgery: A single center experience. Tumori. 2013;99(5):617-622. doi: 10.1700/1377.15312

13. Demiral S, Beyzadeoglu M, Uysal B, Oysul K, Kahya YE, Sager O, et al. Evaluation of stereotactic body radiotherapy (SBRT) boost in the management of endometrial cancer. Neoplasma. 2013;60(3):322-327. doi: 10.4149/neo_2013_043

14. Dincoglan F, Beyzadeoglu M, Sager O, Uysal B, Demiral S, Gamsiz H, et al. Evaluation of linear accelerator-based stereotactic radiosurgery in the management of meningiomas: A single center experience. J BUON. 2013;18(3):717-722.

15. Sager O, Beyzadeoglu M, Dincoglan F, Uysal B, Gamsiz H, Demiral S, et al. Evaluation of linear accelerator (LINAC)-based stereotactic radiosurgery (SRS) for cerebral cavernous malformations: A 15-year single-center experience. Ann Saudi Med. 2014;34(1):54-58. doi: 10.5144/0256-4947.2014.54

16. Sager O, Beyzadeoglu M, Dincoglan F, Gamsiz H, Demiral S, Uysal B, et al. Evaluation of linear accelerator-based stereotactic radiosurgery in the management of glomus jugulare tumors. Tumori. 2014;100(2):184188. doi: $10.1700 / 1491.16409$

17. Dincoglan F, Sager O, Gamsiz H, Uysal B, Demiral S, Oysul K, et al. Management of patients with $\geq 4$ brain metastases using stereotactic radiosurgery boost after whole brain irradiation. Tumori. 2014;100(3):302-306. doi: 10.1700/1578.17210

18. Demiral S, Beyzadeoglu M, Sager O, Dincoglan F, Gamsiz H, Uysal B, et al. Evaluation of linear accelerator (linac)-based stereotactic radiosurgery (srs) for the treatment of craniopharyngiomas. UHODUluslararasi Hematoloji-Onkoloji Dergisi. 2014;24(2):123-129.

19. Gamsiz H, Beyzadeoglu M, Sager O, Dincoglan F, Demiral S, Uysal B, et al. Management of pulmonary oligometastases by stereotactic body radiotherapy. Tumori. 2014;100(2):179-183. doi: 10.1700/1491.16407

20.Sager 0, Dincoglan F, Beyzadeoglu M. Stereotactic radiosurgery of glomus jugulare tumors: Current concepts, recent advances and future perspectives. CNS Oncol. 2015;4(2):105-114. doi: 10.2217/cns.14.56 
21.Gamsiz H, Beyzadeoglu M, Sager O, Demiral S, Dincoglan F, Uysal $B$, et al. Evaluation of stereotactic body radiation therapy in the management of adrenal metastases from non-small cell lung cancer. Tumori. 2015;101(1):98-103. doi: 10.5301/tj.5000222

22. Dincoglan F, Beyzadeoglu M, Sager O, Demiral S, Gamsiz H, Uysal B, et al. Management of patients with recurrent glioblastoma using hypofractionated stereotactic radiotherapy. Tumori. 2015;101(2):179184. doi: $10.5301 /$ tj.5000236

23. Demiral S, Dincoglan F, Sager O, Gamsiz H, Uysal B, Gundem E, et al. Hypofractionated stereotactic radiotherapy (HFSRT) for who grade I anterior clinoid meningiomas (ACM). Jpn J Radiol. 2016;34(11):730737.

24. Dincoglan F, Sager O, Demiral S, Uysal B, Gamsiz H, Dirican B, et al. Radiosurgery for recurrent glioblastoma: A review article. Neurol Disord Therap. 2017;1(4):1-5.

25. Demiral S, Dincoglan F, Sager O, Uysal B, Gamsiz H, Ozcan F, et al. Contemporary Management of Meningiomas with Radiosurgery. Int J Radiol Imaging Technol. 2018;4(2):041. doi: 10.23937/25723235.1510041

26. Koga T, Shin M, Saito N. Role of $\gamma$ knife radiosurgery in neurosurgery: past and future perspectives. Neurol Med Chir (Tokyo). 2010;50(9):737-748.

27. Pollock BE, Stafford SL, Link MJ. Stereotactic radiosurgery of intracranial meningiomas. Neurosurg Clin N Am. 2013;24(4):499-507. doi: 10.1016/j.nec.2013.05.006

28. Demiral S, Sager O, Dincoglan F, Uysal B, Gamsiz H, Dirican B, et al. Evaluation of Target Volume Determination for Single Session Stereotactic Radiosurgery (SRS) of Brain Metastases. Canc Therapy \& Oncol Int J. 2018;12(5): 555848. doi: 10.19080/CTOIJ.2018.12.555848
29. Watts J, Box G, Galvin A, Brotchie P, Trost N, Sutherland T. Magnetic resonance imaging of meningiomas: a pictorial review. Insights Imaging. 2014;5(1):113-122. doi: 10.1007/s13244-013-0302-4

30. Hale AT, Wang L, Strother MK, Chambless LB. Differentiating meningiomagrade by imaging features on magnetic resonance imaging. J Clin Neurosci. 2018;48:71-75. doi: 10.1016/j.jocn.2017.11.013

31. Shimol EB, Joskowicz L, Eliahou R, Shoshan Y. Computer-based radiological longitudinal evaluation of meningiomas following stereotactic radiosurgery. Int J Comput Assist Radiol Surg. 2018;13(2):215-228. doi: 10.1007/s11548-017-1673-7

32. Cohen-Inbar O, Tata A, Moosa S, Lee CC, Sheehan JP. Stereotactic radiosurgery in the treatment of parasellar meningiomas: longterm volumetric evaluation. J Neurosurg. 2018;128(2):362-372. doi: 10.3171/2016.11.JNS161402

33. Surov A, Ginat DT, Sanverdi E, Lim CC, Hakyemez B, Yogi A, et al. Use of Diffusion Weighted Imaging in Differentiating Between Maligant and Benign Meningiomas. A Multicenter Analysis. World Neurosurg. 2016;88:598-602. doi: 10.1016/j.wneu.2015.10.049

34. Tamrazi B, Shiroishi MS, Liu CS. Advanced Imaging of Intracranial Meningiomas. Neurosurg Clin N Am. 2016;27(2):137-43. doi: 10.1016/j.nec.2015.11.004

35. Varlotto J, Flickinger J, Pavelic MT, Specht CS, Sheehan JM, Timek DT, et al. Distinguishing grade I meningioma from higher grade meningiomas without biopsy. Oncotarget. 2015;6(35):38421-38428. doi: 10.18632/oncotarget.5376

36.Zikou A, Alexiou GA, Goussia A, Kosta P, Xydis V, Voulgaris S, et al. The role of diffusion tensor imaging and dynamic susceptibility perfusion MRI in the evaluation of meningioma grade and subtype. Clin Neurol Neurosurg. 2016;146:109-115. doi: 10.1016/j.clineuro.2016.05.005 